\title{
DETECTION OF VENTILATORY ABNORMALITIES IN VARIOUS RESPIRATORY DISEASES
}

\author{
Dumpa Vasudeva Reddy'1, G. Sundar Raj'2, P. Yugandhar 3 , S. Satya Sri ${ }^{4}$
}

${ }^{1}$ Ex-Junior Resident, Department of Pulmonary Medicine, Asram Medical College, Eluru, Andhra Pradesh. ${ }^{2}$ Associate Professor, Department of Pulmonary Medicine, Asram Medical College, Eluru, Andhra Pradesh. 3 Professor, Department of Pulmonary Medicine, Asram Medical College, Eluru, Andhra Pradesh.

${ }^{4}$ Professor \& HOD, Department of Pulmonary Medicine, Asram Medical College, Eluru, Andhra Pradesh.

\begin{abstract}
The study involved 100 patients who presented at Department of pulmonary medicine, Alluri sitaramaraju academy of medical sciences, Eluru between December 2011 and December 2012. Also 100 normal persons were taken in to the study to compare the normal ventilatory function with the standards. There was a male preponderance in the study, about $75 \%$ of the study group were males. The mean height of males in the control group was $164.12 \pm 8.6$ and $152 \pm 5.8 \mathrm{~cm}$ for females. The mean height $(\mathrm{cm})$ of males in the cases was $162 \pm 9.2$ and that of females is $149.6 \pm 4.6$. (Mean \pm SD). The mean age (Years) of smokers in males was 49.05 \pm 12.2 . The ratio of smokers to non-smokers with the study group was 3:2 while that of control group was 2:3. In both the groups, the smokers were moderate to heavy smokers. Most of the subjects in control group had $75 \%$ or above of the standard values for all the parameters studied- FVC, FEV1, FEV 1 /FVC\%. Restrictive ventilatory defect was the most commonly observed ventilatory defect in our study. It was assosciated with most of the diseases studied-pneumonias, mass lesions of the lung, fibrocavities, pleural lesions. Obstructive ventilatory defect was prevalent among asthma and COPD as they are obstructive lung diseases. A mixed ventilatory defect was also seen in this group. Mixed ventilatory defect was seen in most of the post tubercular lesions of the lung- fibrosis, bronchiectasis and mass lesions of the lung. Grading of the severity of disease was done based on international accepted criteria like GINA, GOLD etc. Severity of the ventilatory defect correlated with the severity of various diseases. Some of the patients had normal ventilatory function even in the presence of the disease as the lung has a very large respiratory reserve. Mean FVC, FEV 1 are predominant in males when compared to females in both controls and cases. This may be attributed to the well-built and nourishment among males. The ventilator function parameters (Mean FVC, FEV 1 ) were significantly low in cases in comparision to controls. It may be due to the effect of respiratory illness. FEV ${ }_{1 \%}$ predicted was significantly decreased in obstructive ventilatory defect in cases when compared to controls in both males and females. Spirometry is useful tool in evaluating ventilator function abnormalities in various pulmonary diseases and assessing their severity. This information is useful in management of patients, monitoring and for long term follow up. It helps to understand the physiologic working of lungs and chest mechanics.
\end{abstract}

KEYWORDS: PFT- Pulmonary Function Test.

HOW TO CITE THIS ARTICLE: Dumpa Vasudeva Reddy, G. Sundar Raj, P. Yugandhar, S. Satya Sri. "Detection of Ventilatory Abnormalities in Various Respiratory Diseases". Journal of Evolution of Medical and Dental Sciences 2015; Vol. 4, Issue 88, November 02; Page: 15283-15288, DOI: 10.14260/jemds/2015/2173.

INTRODUCTION: We are living today in a society that is highly advanced urban oriented and industry based. With the rise in industries there is a also a rise in atmospheric pollution. In addition to industries the modern conveyance which has become a part and parcel of our life also add a considerable amount of pollution. These factors along with the rise of smoking habit, show their deleterious effect on human lungs by leading to number of ailments. Today the investigation of respiratory diseases is possible with a variety of diagnostic aids. But the most important are three technological advances that have taken place over the last 200 years from the basis for diagnosing the most respiratory diseases.

The foremost of these is stethoscope which was invented at the beginning of $19^{\text {th }}$ century. It was developed in France by Laennec and it helps us listen what the heart and lungs have to say the basis of auscultation. Then in the middle of the $19^{\text {th }}$ century came the spirometer.

Financial or Other, Competing Interest: None.

Submission 08-10-2015, Peer Review 09-10-2015,

Acceptance 20-10-2015, Published 30-10-2015.

Corresponding Author:

Dr. Dumpa Vasudeva Reddy,

Ho. No. 37-1-434, Ramnagar $1^{\text {st }}$ Lane,

Prakasam Dist, Ongole-523001, A. P.

E-mail:vasu901@gmail.com

DOI:10.14260/jemds/2015/2173
This was developed in England at the Pneumatic Institute, where the pioneering work was done in the field of measuring lung volumes. The first measurement of lung volumes was made by Hutchinson in 1844 when he measured vital capacity of lungs and predicted that VC fell even before audible signs were heard with the stethoscope.

Finally at the end of the 19th century came the discovery that revolutionized the diagnosis of respiratory diseases. It was the discovery of x-ray by Roentgen in 1895. This helped the physician to see exactly what was inside the chest.

So the technology has helped us to hear, measure, and see the lungs promptly without pain. As technological advances, the minds of the people working in various branches of medicine did not lag behind.

Now a day's pulmonary function test is an important routine procedure just like physical examination or x-ray. As has been said before, changes in the PFT can occur even before changes with other investigations.

Another added advantage with PFT is that it gives an objective baseline data for the management of chest diseases and also aids in effective therapy.

Time has come when PFT is not limited to a pulmonary lab and its simpler aspects are used in the domain of routine clinical practice. Yet the most important of pulmonary functions is ventilation and fortunately it can be most easily measured using spirometer. 
Spirometry is a screening procedure. It does not give any etiological diagnosis, but will reveal whether pulmonary function is deviated from normal or not.

So it is high time physicians start supplementing PFT to routine investigations and use it for early identification of respiratory diseases

MATERIALS AND METHODS: The study involved 100 patients of various age groups, socio-economic groups who presented at the Department Of Pulmonary Medicine, Alluri Sitaramaraju Academy of Medical Sciences, Eluru between the period from December 2011 to December 2012.

Patients presenting with various respiratory diseases were selected. The basis for selecting the patient was that the sputum was negative for AFB and they did not give history of any previous cardiac illness. All the patients selected for the study were given a complete physical checkup. If during the physical examination they were suspected to have any cardiac illness, an ECG was taken if any cardiac illness was found to be present, the subject was excluded from the study.

After ruling out the cardiac disease, the patient was included in the study. All the patients so selected for the study were subjected to routine investigations like blood for HB\%, TC, DC, ESR, RBS, Blood Urea, Urine for albumin and sugar. Then the patient's height and weight were recorded. A detailed occupational and smoking history was taken for each patient.

Then each of the patient was asked to perform the forced expiratory maneuver with Minispir spirometer. The spirometer is calibrated and is turbine driven electronic spirometer which automatically gives the best result on the spirogram. Spirograms were then obtained for each patient. Three parameters were considered in the study. These are FVC-Forced vital capacity, $\mathrm{FEV}_{1}$-Forced expiratory volume in one second, $\mathrm{FEV}_{1} \%-\mathrm{FEV}_{1} / \mathrm{FVC} \times 100$. The nature of ventilatory defect was recorded for each patient. Based on the clinical findings, the patients disease is diagnosed and the nature of ventilatory defect was used to classify the disease as normal, obstructive, restrictive or mixed ventilatory defect.

Also 100 normal healthy persons with no respiratory or cardiac symptoms were also included in the study to serve as controls. This group was comparable to the patient group in the sex, age and smoking history. The control group was subject to thorough physical examination, Chest x-ray and ECG to rule out any respiratory or cardiac pathology. If they had any respiratory or cardiac pathology they were excluded. So the 100 people were also asked to perform the forced expiratory maneuver. Their values were then compared with the standard values to serve as controls for the study group. This was done because spirometer was calibrated in Italy to BTPS (Body, Temperature, Pressure, Saturated with water vapour) and mainly for Caucasians.

As the Indians have less body surface than Caucasians, they would normally be expected to have lower values and all the persons would fall in abnormal ranges. So this control group would help to partly overcome the defect and form an Indian standard to compare the study group. Statistical analysis was done using student t-test. The results were given as Mean \pm Standard Deviation. The $\mathrm{p}$ value of 0.05 or less was considered as statistically significance.
DISCUSSION: In the present study, 100 cases who presented at the Department of Pulmonary Medicine, over a period of 1 year from December 2011 to December 2012 were included.

Out of 100 cases, 78 were males 22 were females. The male to female ratio is approximately $4: 1$. The more number of male patients were present in the study group because, males come more frequently to the OPD and also the smoking was more common among males. As smoking has a direct detrimental effect on the lung function, males were more in number in the study. The fact had been highlighted by the study done by Mirza et al.(1) they studied 200 cases out of which 120 males and 80 females were noted. The ratio accounted for 3:2.

The ratio of smokers to non-smokers in the study group was 62:38 approximately 3:2. The number of smokers among studied population was $62 \%$. The ratio of smoking among male subjects was $58 \%$ and in female $4 \%$. In smokers male to female ratio was approximately 14:1. Prevalence of smoking was higher among males than females. Similar findings were noted in the study done by Boskabadt et al where the rate of smoking among male subjects was $17.2 \%$ and in female $2.5 \%$.

The mean \pm SD values of FVC (L) was $2.76 \pm 0.67$ in smokers, $3.10 \pm 0.79$ in non-smokers and that of $\mathrm{FEV}_{1}$ was $2.32 \pm 0.59$ in smokers, $2.72 \pm 0.11$ in non-smokers in controls. Our finding was coinciding with the study done by Miller A et al.(2) where FVC was more decreased in current smokers when compared to exsmokers and non-smokers.

Similar findings were observed in the study by Nancy NR et.(3) al where FVC and FEV1 were significantly lower in smoking group as compared to non-smokers.

100 Normal persons were also taken into the study to compare the ventilatory function of the study group with the normal subjects. It was seen that most of the persons in the control group had $75 \%$ or more of the standard values for the various parameters studied.

In study group COPD (11\%), asthma (19\%), pneumonia (15\%), pleural diseases (23\%), bronchiectasis (5\%), fibrosis (14\%), fibrocavitary lesions (8\%), mass lesions (5\%) were present.

COPD is characterized by airflow limitation which is usually progressive and is associated with an abnormal inflammatory response of lungs to noxious particles or gases. It is of 2 types, Emphysema in which there is abnormal permanent enlargement of airspaces distal to the terminal bronchioles with destruction of walls with or without fibrosis. In pulmonary emphysema, the maximal ventilator capacity is reduced the other pattern is chronic bronchitis where there is cough with expectoration on most days for atleast 3months during two or more consecutive years. This is characterized by excessive mucus secretions of the tracheobronchial tree. In chronic bronchitis, the ventilatory function may be normal or an obstructive pattern is observed.

In our study of 11 COPD patients $1(9 \%)$ patient had normal ventilatory function. This can be explained on the basis of normal ventilatory function seen in chronic bronchitis. $2(18 \%)$ patients presented with mild obstruction, $4(36 \%)$ patients with severe obstruction, $2(18 \%)$ patients with restriction and $2(18 \%)$ patients with mixed obstruction and restriction. The reason for the combined defect and restriction was the presence of fibrosis as a sequeale of TB. All the COPD cases in study group are smokers. In study group COPD was present in $11 \%$ and among smokers it was $22 \%$. Majority of them had obstructive ventilatory defect (54.5\%). 
The mean and variance of FVC (L) and FEV1 (L) in our study in COPD patients were $2.157 \pm 1.088$ and $1.23 \pm 0.39$. There is statistical significance $(\mathrm{p}<0.05)$ in both FVC and FEV1 when compared to controls where FVC is $2.76 \pm 0.45$ and FEV1 is $2.32 \pm 0.35$ in male smokers. This significance was high in FEV1 than FVC which characterizes the obstructive ventilatory defect in COPD. Similar findings observed in study done by Mannino et al.(4) where obstructive lung disease was more common among current smokers compared to ex-smokers and non-smokers.

The mean level of lung function and FEV1 was always lower among current smokers and former smokers compared with non-smoker.

The results of study done by shahab I et al were coinciding with our findings where spirometry defined COPD was present in $13.3 \%$ of participants. A total of $34.9 \%$ of people with spirometry defined COPD were smokers.

Similar findings were observed in study done by Pelkonen $\mathrm{M}$ et al.(5) where cumulative incidence of chronic bronchitis and COPD were $42 \%$ and $32 \%$ respectively in continuous smokers as compared to $26 \%$ and $14 \%$ in exsmoker and $22 \%$ and $12 \%$ in non-smokers.

Asthma is chronic inflammatory disorder of airways with airway hyper responsiveness and variable airway obstruction. In addition to airway obstruction, the airways are obstructed with thick mucus plugs which further cause obstruction of the airways.

But, this pattern of obstruction is seen only when the patient is having an acute attack. In the intermittent period, patient may be normal.

In our study, 19 patients with asthma were present. Among 19 cases $7(36.84 \%)$ patients had intermittent bronchial asthma. All of the 7 cases had normal ventilatory function. This can be explained from the fact that they may be in the intermittent symptom free period. $4(21.05 \%)$ patients had mild persistent bronchial asthma. Among 4 patients $2(50 \%)$ had normal ventilator function, mild obstruction in $1(25 \%)$ and mild restriction in $1(25 \%)$ case. $3(15.78 \%)$ cases had moderate persistent asthma. Among 3 cases moderate severe obstruction in $1(33.33 \%)$, moderate restriction in $1(33.33 \%)$, mixed obstructive and restrictive ventilatory defect in $1(33.33 \%)$ were preent. Severe persistent bronchial asthma was present in 5 (26.31\%) cases. Among them 2(40\%) had severe obstruction and $3(60 \%)$ had mixed obstructive and restrictive ventilatory defect. Among the 19 bronchial asthma patients 9(47.3\%) had normal ventilatory function, $4(21 \%)$ cases had varying degree of obstruction. Mild obstruction in 1(5\%), moderate severe obstruction in $1(5 \%)$ and severe obstruction in $2(10 \%)$ patients were present. $4(21 \%)$ cases had mixed obstructive and restrictive ventilatory defect, $2(10 \%)$ cases had restrictive defect. This can be explained by the fact that 4 of them were old TB patients with sequelae like fibrosis which was coexistent with bronchial asthma causing restrictive defect. In our study obstructive pattern was found in $21 \%$ of patients, normal pattern in $47.4 \%$, restrictive in $10.5 \%$ and mixed pattern in $21 \%$.

The findings observed in study group were correlating with study done by Tarig Merghani et al (2012) where a sample of 177 known asthmatic patients ( 96 females and 81 males) was selected and FEV1, FVC, FEV1/FVC ratio and PEF measurements for each patient were carried out, according to American Thoracic Society. $(6,7,8,9)$ guidelines, Typical obstructive pattern was found in only $26.6 \%$ of patients, normal pattern in $19.8 \%$, restrictive in $33.3 \%$ and combined pattern in $20.3 \%$.Pneumonia is an inflammation of lung parenchyma. During the stages of red and grey hepatisation, the alveoli are filled with exudates which cause a fall in ventilatory parameters. There will also be a concomitant pleural pain that further reduces lung compliance. Also there may be an associated synpneumonic effusion which compresses the lung and further reduces its volume.

In our study, a total of 15 cases of pneumonia were present of which $5(33 \%)$ patients had normal ventilatory function. The remaining 10(66\%) patients showed a restrictive pattern of which $3(20 \%)$ had mild restriction $5(33 \%)$ had moderate restriction and $2(13 \%)$ had severe restriction. This can be explained by the fact that the respiratory reserve is very large and sufficient amount of lung tissue had to be involved to cause the ventilatory abnormality. In the 2 cases that showed severe restriction one patient had massive pneumonia and other had an associated effusion.

Pleural lesions cause compression of the lung and hence reduces its volumes leading to a restrictive ventilatory defect. The causes of pleural lesions are many fold. But in India, the most common cause of pleural lesions is tuberculosis.

As TB causes parenchymal lesions also, pleural lesions can have purely restrictive defect or may have an assosciated obstructive defect as a consequence of pulmonary TB. The pleural lesions associated with mass lesions can also have a mixed defect due to compression of the airways by mass of lung itself or by mediastinal nodes.

In our study, 23 cases of pleural lesions were noted of which 18(78\%) had pleural effusions, 2(9\%) had hydropneumothorax and 3(13\%) had empyema. Of these 18 effusions, $8(34 \%)$ were of TB etiology. Among these 8 cases mild restriction in 1 , moderate restriction in 3 , severe restriction in 2, mixed obstruction and restriction in 2 cases were present.

In tuberculosis effusions with mixed ventilatory defect, the lung parenchyma was also involved with fibrosis leading to narrowing of airways. 3(13\%) cases had associated mass lesions, 2 of them were bronchogenic carcinoma cases who had mixed obstruction and restriction and 1 had pulmonary metastatis with moderate restriction. In patients with mass lesions, the mixed defect may be due to compression of airway. 3 cases (13\%) had an associated collapse, 2 of them were due to malignancy and 1 had endobronchial tuberculosis who had mixed obstruction and restriction ventilatory defect. 4(17\%) cases were bilateral effusions, 3 of them had congestive cardiac failure with moderate restriction in 1 , severe restriction in 2 and 1 had renal failure with moderate restriction.

$2(9 \%)$ cases were hydropneumothorax of tuberculous etiology who had severe restriction. 3(13\%) empyema cases were present, out of which 2 cases were of tuberculosis who had severe restriction in 1, mixed restriction and obstruction in 9 and 1 case was non tuberculous empyema due to staphylococcus aureus who had mixed restriction and obstruction ventilatory defect. The mixed defect here can also be explained on the lines of tuberculosis sequeale resulting in damage to airways. The findings in the study group are correlating with the study done by Kulwant S. Bhatia et al.(10) where pleural effusion cases had restrictive ventilatory defect and small airway obstructive pattern on spirometry.

Other parenchymal lesions included in the study are fibrosis and fibrocavities. These are mainly sequeale of pulmonary TB. These lesions were due to destruction of lung parenchyma resulting in restrictive ventilatory defect. 
In addition to this the airways are also stretched and distorted in the process of fibrosis. So there is also an obstruction defect in addition to the restrictive defect.

In our study 14 cases of fibrosis were present, out of which $1(7.14 \%)$ had minimal fibrosis with moderate restriction, $3(21.42 \%)$ had moderate fibrosis with severe restriction in 2 cases and mixed obstruction and restriction in 1 case, $10(71.42 \%)$ had extensive fibrosis with severe restriction in 6 cases and mixed obstruction and restriction in 4 cases.

8 cases of fibrocavities were also studied, out of which $2(25 \%)$ had moderate lesion with mild restriction in 1 and moderate restriction in 1 and $675 \%$ ) cases had extensive lesion with severe restriction.This can be explained on the basis of parenchymal pathology leading to a loss of lung volume.

In our study 5 cases of bronchiectasis were present. Localized bronchiectasis was present in $1(20 \%)$ case who had mild restriction. Diffuse bronchiectasis was present in $4(80 \%)$ cases with severe restriction in 1 case and mixed obstruction and restriction in 3 cases. This can be explained by the fact that in addition to airway damage, parenchymal destruction is also present in bronchiectactic process.

In the view of strict diagnostic criteria to confirm bronchiectasis i.e, HRCT confirmation and exclusion of other assosciated conditions like COPD, Pneumonia, Bronchial Asthma, mass lesion, Tuberculosis could have resulted in few cases of bronchiectasis.

In the study done by Chi Young Jung, MD et al.(11) on patients with tuberculous destroyed lung obstructive ventilatory defects were observed in 31 cases (70.5\%), followed by mixed ventilatory defect $(n=7)$ and restrictive ventilatory defect $(n=5)$. They concluded that the patient with tuberculous destroyed lung showed obstructive ventilatory defect commonly and it may be due to bronchiectasis and emphysema on CT scan. There was negative correlation between the extent of destruction of lung and lung function.

In contrast most of the cases in our study with post tuberculous sequelae like fibrosis (64.3\%), fibrocavitary lesions (100\%) restrictive pattern was observed. Mixed obstructive and restrictive pattern was observed in $35.7 \%$ cases of fibrosis and $60 \%$ cases of bronchiectasis.

Mass lesions of the lung usually have restrictive ventilation defect depending on the size of the lesion. Also there may be assosciated obstruction due to compression of airways by the mass itself or by the mediastinal nodes. Also most of the patients with mass lesion have a history of smoking which contributes to COPD.

In our study we had 5 mass lesions of which $1(20 \%)$ had moderate restriction and $4(80 \%)$ had mixed restriction and obstruction. The above explanation satisfies the finding in our study. In our study the predominant ventilatory abnormality was mixed pattern because of coexisting COPD. In our study few cases of mass lesion were present during study period of 1 year as it is a rural private medical college and most of them belong to low socio economic group.

In the study group mixed obstructive and restrictive ventilatory defect is observed in $27 \%$ of cases. Out of which asthma (14.8\%), COPD (9.5\%), bronchiectasis (11.1\%), fibrosis $(18.5 \%)$, mass lesions $(14.8 \%)$, pleural diseases $(33.3 \%)$ were noted. In india TB burden is one fifth of the world and it is more common than other pulmonary diseases such as COPD.
Mixed obstructive and restrictive ventilator defect in study group is coinciding with the study done by Diaz Guzman E et al.(12) where they concluded that mixed obstruction and restriction occurs infrequently and is more commonly caused by a combination of pulmonary parenchymal and non-pulmonary disorders.

In the study group restrictive defect (48\%), obstructive $(10 \%)$, mixed ventilatory defect $(27 \%)$, normal $(15 \%)$ were present. Restrictive ventilatory defect is common than mixed and obstructive cases.

Our study is correlating with the study done by Chattopadhyay et al on respiratory morbidity pattern in people exposed to auto exhaust. Results showed restrictive (37.6\%), obstructive (31.7\%), and combined defect in $19.8 \%$ people where restrictive defect was common than others.

Even in health there is wide variation in pulmonary function parameters so this is understandable as there is a difference in PFT parameters in those with different diseases such as asthma, COPD, pneumonia, pleural and other lung diseases. Our study has shown that PFT is useful in knowing the type of defect whether obstructive, restrictive or mixed defect and severity of disease. It is helpful in the management of patients and targeting therapy.

\section{BIBLIOGRAPHY:}

1. Mirza Ikram Ali Baig and Riaz H Qureshi. Pulmonary Function Tests: Normal values in non-smoking students and staff at the AGA Khan University, Karachi. JCPSP 2007; 17(5): 265-68.

2. Miller A, Liilis P, Godbold, Chan E, Wu X, Selikoff I J. Spirometric impairments in long term insulators relationships of duration of exposure, smoking and radiographic abnormalities. Chest 1994; 105:175-82.

3. Nancy NR, Rai UC. A Study of forced expiratory spirogram in south Indian beedi smokers and cigarette smokers. Ind J Chest Diseases \& Allied Sci 1981; 31:25-30.

4. Mannino DM, Gagnon RC, Petty TL, Lydick E. Obstructive lung disease and low lung function in adults in the United States. Arch Intern Medi 2000; 160:1683-89.

5. Pelkonen M, Notkola I, Nissinen A, Tukiainen H. Thirtyyear cumulative incidence of chronic bronchitis and COPD in relation to 30 Year pulmonary function and 40-Year mortality. Chest 2006;130:1129-37

6. American Thoracic Society. Standardization of spirometry. Am Rev Respir Dis 1979; 119: 831-838.

7. American Thoracic Society. Standardization of Spirometry: 1994 update. Am J Respir Crit Care Med 1995; 152:1107-1136.

8. American Thoracic Society. Evaluation of impairment/ disability secondary to respiratory disorders. Am Rev Respir Dis 1986; 133: 1205-1209.

9. American Thoracic Society. Guidelines for the evaluation of impairment/disability in patients with asthma. Am Rev Respir Dis 1993; 147: 1056-1061.

10. Kulwant S. Bhatia, MD; Sanjeev Kumar Kapoor. Spirometric Evaluation in Patients with Tuberculous Pleural Effusion Before, During and After Chemotherapy. Chest. 2003;124:218. 
11. Chi Young Jung, MD; Young June Jeon, MD; Byung Hak Rho, MD. Radiologic Findings and Lung Function in Patients with Tuberculous Destroyed Lung. Chest. 2011; 140:766.
12. Diaz-Guzman E, McCarthy K, Siu A, Stoller JK. Frequency and causes of combined obstruction and restriction identified in pulmonary function tests in adults. Respir Care. 2010 Mar; 55(3):310-6.

RESULTS:

\begin{tabular}{|c|c|c|c|c|c|}
\hline \multirow{2}{*}{ MALES } & \multirow{2}{*}{$\mathbf{n}$} & \multicolumn{2}{|c|}{ Age (years) } & \multicolumn{2}{c|}{ Height (cm) } \\
\cline { 3 - 6 } & & Range & Mean \pm SD & Range & Mean \pm SD \\
\hline Controls & 68 & 45 & $36.29 \pm 10.9$ & 35 & $164.12 \pm 8.6$ \\
\hline cases & 78 & 56 & $47.28 \pm 13.4$ & 40 & $162 \pm 9.2$ \\
\hline \multicolumn{3}{|c}{ Table 1: Mean age and height of males in the study } \\
\hline
\end{tabular}

\begin{tabular}{|c|c|c|c|c|c|}
\hline \multirow{2}{*}{ FEMALES } & \multirow{2}{*}{$\mathbf{n}$} & \multicolumn{2}{|c|}{ Age (years) } & \multicolumn{2}{c|}{ Height (cm) } \\
\cline { 3 - 6 } & & Range & Mean \pm SD & Range & Mean \pm SD \\
\hline Controls & 32 & 41 & $37.96 \pm 12.7$ & 22 & $151 \pm 5.8$ \\
\hline cases & 22 & 55 & $47.27 \pm 16.2$ & 18 & $149.64 \pm 4.6$ \\
\hline \multicolumn{3}{|c|}{ Table 2: Mean age and height of females in the study } \\
\hline
\end{tabular}

The ratio of smokers to non-smokers is 62:38, approximately $3: 2$.

The mean age (years) of smokers in males was $49.05 \pm 12.2$.

\begin{tabular}{|c|c|c|c|c|c|c|}
\hline & \multicolumn{3}{|c|}{ Males } & \multicolumn{3}{c|}{ Females } \\
\cline { 2 - 7 } & $\mathbf{2 0 - 3 9 \mathbf { y }}$ & $\mathbf{4 0}-\mathbf{5 9} \mathbf{y}$ & $\geq \mathbf{6 0} \mathbf{y}$ & $\mathbf{2 0}-\mathbf{3 9} \mathbf{y}$ & $\mathbf{4 0}-\mathbf{5 9} \mathbf{y}$ & $\geq \mathbf{6 0} \mathbf{~}$ \\
\hline $\mathrm{FVC}(\mathrm{L})$ & $2.42 \pm 1.00$ & $1.54 \pm 0.64$ & $1.99 \pm 0.62$ & $1.35 \pm 0.17$ & $1.24 \pm 0.12$ & $1.18 \pm 0.31$ \\
\hline $\mathrm{FEV}_{1}(\mathrm{~L})$ & $2.22 \pm 0.83$ & $1.13 \pm 0.47$ & $1.43 \pm 0.31$ & $1.28 \pm 0.17$ & $0.98 \pm 0.16$ & $0.69 \pm 0.04$ \\
\hline $\mathrm{FEV}_{1} / \mathrm{FVC} \%$ & $0.86 \pm 0.01$ & $0.72 \pm 0.05$ & $0.75 \pm 0.02$ & $0.96 \pm 0.01$ & $0.77 \pm 0.032$ & $0.72 \pm 0.07$ \\
\hline \multicolumn{7}{|c|}{ Table 3: Age wise distribution of Mean and } \\
variance of FVC, FEV1 and FEV1/FVC\% in cases \\
\hline
\end{tabular}

\begin{tabular}{|c|c|c|c|c|c|c|c|c|}
\hline $\begin{array}{c}\text { BRONCHIAL } \\
\text { ASTHMA } \\
\text { (GINA 2012) }\end{array}$ & Normal & $\begin{array}{c}\text { Mild } \\
\text { Obstruction }\end{array}$ & $\begin{array}{c}\text { Moderate } \\
\text { Obstruction }\end{array}$ & $\begin{array}{c}\text { Moderate } \\
\text { Severe } \\
\text { obstruction }\end{array}$ & $\begin{array}{c}\text { Severe } \\
\text { Obstruction }\end{array}$ & $\begin{array}{c}\text { Mild } \\
\text { Restrict } \\
\text { ion }\end{array}$ & $\begin{array}{c}\text { Moderate } \\
\text { Restriction }\end{array}$ & $\begin{array}{c}\text { Obstruction } \\
+ \\
\text { Restriction }\end{array}$ \\
\hline Intermittent & 7 & 0 & 0 & 0 & 0 & 0 & 0 & 0 \\
\hline $\begin{array}{c}\text { Mild } \\
\text { persistent }\end{array}$ & 2 & 1 & 0 & 0 & 0 & 1 & 0 & 0 \\
\hline $\begin{array}{c}\text { Moderate } \\
\text { Persistent }\end{array}$ & 0 & 0 & 0 & 1 & 0 & 0 & 1 & 1 \\
\hline $\begin{array}{c}\text { Severe } \\
\text { Persistent }\end{array}$ & 0 & 0 & 0 & 0 & 2 & 0 & 0 & 3 \\
\hline TOTAL & $\mathbf{9}$ & $\mathbf{1}$ & $\mathbf{0}$ & $\mathbf{1}$ & $\mathbf{2}$ & $\mathbf{1}$ & $\mathbf{1}$ & $\mathbf{4}$ \\
\hline
\end{tabular}

\begin{tabular}{|c|c|c|c|c|c|c|}
\hline Total & Normal & $\begin{array}{c}\text { Mild } \\
\text { Obstruction }\end{array}$ & $\begin{array}{c}\text { Severe } \\
\text { Obstruction }\end{array}$ & $\begin{array}{c}\text { Mild } \\
\text { Restriction }\end{array}$ & $\begin{array}{c}\text { Moderate } \\
\text { Restriction }\end{array}$ & $\begin{array}{c}\text { Obstruction + } \\
\text { Restriction }\end{array}$ \\
\hline 11 & 1 & 2 & 4 & 1 & 1 & 2 \\
\hline \multicolumn{7}{|c|}{ Table 5: Ventilatory abnormality in COPD } \\
\hline
\end{tabular}

\begin{tabular}{|c|c|c|c|c|c|}
\hline Total & Normal & $\begin{array}{c}\text { Mild } \\
\text { Restriction }\end{array}$ & $\begin{array}{c}\text { Moderate } \\
\text { Restriction }\end{array}$ & $\begin{array}{c}\text { Severe } \\
\text { Restriction }\end{array}$ & Obstruction + Restriction \\
\hline 15 & 5 & 3 & 5 & 2 & - \\
\hline \multicolumn{6}{|c|}{ Table 6: Ventilatory abnormality in Pneumonia } \\
\hline
\end{tabular}

\begin{tabular}{|c|c|c|c|c|}
\hline BRONCHIECTASIS & $\begin{array}{c}\text { Mild } \\
\text { Restriction }\end{array}$ & $\begin{array}{c}\text { Moderate } \\
\text { Restriction }\end{array}$ & $\begin{array}{c}\text { Severe } \\
\text { Restriction }\end{array}$ & Obstruction + Restriction \\
\hline Localized & 1 & 0 & 0 & 0 \\
\hline Diffuse & 0 & 0 & 1 & 3 \\
\hline TOTAL & $\mathbf{1}$ & $\mathbf{0}$ & $\mathbf{1}$ & $\mathbf{3}$ \\
\hline \multicolumn{7}{r}{ Table 7: Ventilatory abnormality in Bronchiectasis } \\
\end{tabular}

Localized Bronchiectasis: Disease limited to one lobe or segment.

Diffuse Bronchiectasis: Disease involving more than one lobe and/or bilateral. 


\begin{tabular}{|c|c|c|c|c|}
\hline FIBROSIS OF LUNG & $\begin{array}{c}\text { Mild } \\
\text { Restriction }\end{array}$ & $\begin{array}{c}\text { Moderate } \\
\text { Restriction }\end{array}$ & $\begin{array}{c}\text { Severe } \\
\text { Restriction }\end{array}$ & Obstruction + Restriction \\
\hline Miniimal & 0 & 1 & 0 & 0 \\
\hline Moderate & 0 & 0 & 2 & 1 \\
\hline Extensive & 0 & 0 & 6 & 4 \\
\hline TOTAL & 0 & 1 & 8 & 5 \\
\hline \multicolumn{7}{|l}{ Table 8: Ventilatory abnormality in Fibrosis } \\
\hline
\end{tabular}

Minimal: Fibrosis involving $\leq 1$ zone in X-Ray Chest.

Moderate: Fibrosis involving $>1-<3$ zones in X-Ray Chest.

Extensive: Fibrosis involving $\geq 3$ zones in $\mathrm{X}$-Ray Chest.

\begin{tabular}{|c|c|c|c|c|}
\hline FIBROCAVITARY LESION OF LUNG & $\begin{array}{c}\text { Mild } \\
\text { Restriction }\end{array}$ & $\begin{array}{c}\text { Moderate } \\
\text { Restriction }\end{array}$ & $\begin{array}{c}\text { Severe } \\
\text { Restriction }\end{array}$ & Obstruction + Restriction \\
\hline Moderate & 1 & 1 & 0 & 0 \\
\hline Extensive & 0 & 0 & 6 & 0 \\
\hline TOTAL & 1 & 1 & 6 & 0 \\
\hline \multicolumn{2}{r|}{ Table 9: Ventilatory abnormality in Fibrocavity } \\
\hline
\end{tabular}

Moderate: Cavity size $<4 \mathrm{~cm}$ and fibrosis of lung.

Extensive: Cavity size $\geq 4 \mathrm{~cm}$ and fibrosis of lung.

\begin{tabular}{|c|c|c|c|c|}
\hline MASS LESION & $\begin{array}{c}\text { Mild } \\
\text { Restriction }\end{array}$ & $\begin{array}{c}\text { Moderate } \\
\text { Restriction }\end{array}$ & $\begin{array}{c}\text { Severe } \\
\text { Restriction }\end{array}$ & Obstruction + Restriction \\
\hline Mass lesion with assosciated COPD & 0 & 0 & 0 & 4 \\
\hline Mass lesion without assosciated COPD & 0 & 1 & 0 & 0 \\
\hline TOATAL Table 10: Ventilatory abnormality in Mass lesions \\
\hline \multicolumn{4}{r}{} \\
\hline
\end{tabular}

\begin{tabular}{|c|c|c|c|c|c|}
\hline PLEURAL DISEASES & Total & Mild restriction & Moderate restriction & Severe restriction & $\begin{array}{l}\text { Obstruction + } \\
\text { restriction }\end{array}$ \\
\hline \multicolumn{6}{|c|}{ Pleural Effusion With Mass } \\
\hline $\begin{array}{l}\text { Bronchogenic } \\
\text { carcinoma }\end{array}$ & 2 & 0 & 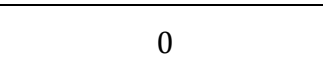 & $\mathbf{0}$ & 2 \\
\hline Metastatic lesion & 1 & 0 & 1 & $\mathbf{0}$ & $\mathbf{0}$ \\
\hline \multicolumn{6}{|c|}{ Pleural Effusion With Collapse } \\
\hline Malignancy & 2 & 0 & 0 & $\mathbf{0}$ & 2 \\
\hline Endobronchial TB & 1 & 0 & 0 & $\mathbf{0}$ & 1 \\
\hline \multicolumn{6}{|c|}{ Bilateral Pleural effusion } \\
\hline $\begin{array}{l}\text { Congestive cardiac } \\
\text { failure }\end{array}$ & 3 & 0 & 1 & 2 & $\mathbf{0}$ \\
\hline Renal failure & 1 & 0 & 1 & $\mathbf{0}$ & $\mathbf{0}$ \\
\hline $\begin{array}{c}\text { Tuberculous Pleural } \\
\text { effusion }\end{array}$ & 8 & 1 & 3 & 2 & 2 \\
\hline \multicolumn{6}{|c|}{ Empyema } \\
\hline Tuberculous & 2 & 0 & 0 & 1 & 1 \\
\hline Non Tuberculous & 1 & 0 & 0 & $\mathbf{0}$ & 1 \\
\hline $\begin{array}{l}\text { Hydropneumothorax } \\
\text { (Tuberculosis) }\end{array}$ & 2 & 0 & 0 & 2 & $\mathbf{0}$ \\
\hline TOTAL & 23 & 1 & 6 & 7 & 9 \\
\hline \multicolumn{6}{|c|}{ Table 11: Ventilatory abnormality in Pleural diseases } \\
\hline
\end{tabular}

